\title{
Photothermal infrared thermography applied to the non- destructive characterisation of the interface between liners and engine blocks
}

\author{
By Peggy LALOUE ${ }^{1}$, Jean-François HENRY ${ }^{1}$, Hervé PRON ${ }^{1}$, Jacques \\ L'ECOLIER $^{2}$, François NIGON ${ }^{2}$ and Christian BISSIEUX ${ }^{1}$ \\ ${ }^{1}$ Université de Reims, Unité de Thermique et Analyse Physique, EA 2061 \\ Laboratoire de Thermophysique (URCA/UTAP/LTP) \\ UFR Sciences, Moulin de la Housse, BP 1039, 51687 REIMS Cedex 2 \\ Phone: 33/0 326913300 - e-mail jf.henry@univ-reims.fr \\ ${ }^{2}$ PSA Peugeot Citroën \\ Laboratoire Optique et Thermique \\ 45 rue Jean-Pierre Timbaud, 78300 POISSY \\ Phone: 33/0 130195494 - e-mail : francois.nigon@mpsa.com
}

\begin{abstract}
:
The aim of the present study is to characterize the variations of thermal resistances between liners and engine blocks of cars; a non-destructive evaluation is proposed: photothermal infrared thermography.

The thermal response of the sample submitted to a modulated optical stimulation is measured by means of an infrared camera. Then, a numerical lock-in procedure yields both amplitude and absolute phase maps of the thermal field periodic component.

On the one hand, an analytical modelling, associated with an inverse procedure using the Gauss-Newton parameter estimation method, allows the identification of the thermal resistance on academic samples, representative of the liner-engine block interface. On the other hand, the implementation of a numerical modelling allows studying two-dimensional defects at the cast iron-aluminium interface.

Finally, the method is applied to liner-engine block interfaces. The measured thermal resistances match the values obtained when a cast iron plate and an aluminium plate are pressed together.
\end{abstract}

Keywords: infrared thermography / thermal resistance / metal - metal interface / lockin procedure / thermal modelling

\section{Introduction}

The present work aims to characterize the variable thermal resistances between liners and engine blocks, and to quantify eventual air layers that could impede the engine cooling. Since this problem is essentially of thermal nature, photothermal infrared thermography appears to be particularly relevant here. In addition, this nondestructive technique is not disturbed by surface roughness and allows both excitation and detection to be applied on the same side. 
The study of the contact between two joined metals has been approached in transient mode with the brief signal method [1]. Then, the use of a periodic thermal field for thermal resistance measurements by thermocouples, initiated by SaintBlanquet [2] in 1970, has been extended to measurements by photothermal radiometry. For example, this method enabled to characterize crimped metal tubes [3].

On the one hand, an analytical modelling, associated with an inverse procedure using the Gauss-Newton parameter estimation method, allows the identification of the thermal resistance on academic samples, representative of the liner-engine block interface. On the other hand, the implementation of a numerical modelling allows studying two-dimensional defects at the cast iron-aluminium interface. The thermal resistance (or the equivalent air layer thickness) at the interface is identified by an inverse procedure using the Gauss - Newton parameter estimation method. Finally, the method is applied to the characterization of a linerengine block interface.

\section{Experimental set-up and thermal modelling}

\subsection{Description and validation of the experimental device}

Figure 1 illustrates the non-destructive experimental system jointly developed by PSA and the University of Reims (URCA/UTAP/LTP). The sample is submitted to a sinusoidal excitation obtained thanks to a set of four spotlights. Then, the thermal response is measured by means of an infrared camera and a photodiode takes simultaneously the optical reference signal. A numerical lock-in procedure $[4,5,6]$ yields both amplitude and absolute phase maps of the periodic thermal field, for modulation frequencies ranging from $10^{-3} \mathrm{~Hz}$ to a few $\mathrm{Hz}$.

\subsection{Analytical thermal modelling}

The thermal phenomenon analysis has been first realised by an analytical modelling of a one-dimensional multilayer. This model allows the calculation of the sample response to a periodic excitation, and to obtain both phase and amplitude theoretical values of the temperature response.

The considered sample is made up of a sprayed paint (to increase and homogenize the emissivity) on a cast iron plate, which is separated from an aluminium plate by an air layer of variable thickness (figure 2). Equivalence between a two-layer model with contact thermal resistance and a three-layer model with a central air layer at the interface had already been established [3]. Similar results were obtained here with an additional layer representing the emissive deposit at the front surface.

Thanks to a study of sensitivity to the different parameters, the optimal experimental conditions for air layer detection at the cast iron-aluminium interface have been determined. This study has pointed out the important phase sensitivity to the paint layer thickness variations. So, another black and matt deposit, the applying technique of which guarantees a controlled uniform thickness, has finally been chosen: the phosphatation. Figure 3 shows the evolution of the phase sensitivity to contact thermal resistance, as a function of modulation frequency. The sodetermined relevant frequency domain of investigation is ranged between $0.01 \mathrm{~Hz}$ and $2 \mathrm{~Hz}$.

If the resistance increases beyond $410^{-3} \mathrm{~K} \cdot \mathrm{m}^{2} . \mathrm{W}^{-1}$ (100 $\mu \mathrm{m}$-thick air layer), the phase sensitivity becomes nearly zero. The photothermal method proves to be 
particularly sensitive to values of resistance between $410^{-6}$ and $410^{-3} \mathrm{~K}^{-\mathrm{m}^{2}}$.W $\mathrm{W}^{-1}$ (equivalent air layer between 0.1 and $100 \mu \mathrm{m}$ ). In this range, the sensitivity is $410^{-6}$ $\mathrm{K} . \mathrm{m}^{2} \cdot \mathrm{W}^{-1}$ for a phase shift of 1 degree, which is, in first approximation, the accuracy of a phase measurement.

The inverse procedure associated with this model is based on the GaussNewton parameter estimation method according to ordinary least squares [Beck \& Arnold, 7]. The confidence intervals, resulting only from the theory-experiment adjustment, are given with a risk of $10 \%$.

The use of a 1D analytical model supposes a uniform distribution of the incident flux on the whole sample surface. However, this condition is quite difficult to obtain scrupulously in practice. In order to take into account the lateral heat diffusion introduced by a non-uniform incident flux, another analytical modelling has been realised under axis-symmetrical conditions. This kind of model describes the behaviour of a sample structured in parallel layers, and exposed to a Gaussian incident flux.

\subsection{Numerical thermal model}

Moving on to a multidimensional numerical model is essential to account for located defects or non-uniform thermal resistance at the cast iron-aluminium interface. An axi-symmetrical 2D numerical model, using ABAQUS ${ }^{\mathrm{TM}}$ finite element software, has been developed then validated thanks to a comparison with the corresponding analytical model. A resistive defect has been simulated at the sample centre. The calculated phase evolution along a radius (for a modulation frequency of $0.2 \mathrm{~Hz}$ ) is shown on figure 4 . At a frequency of $0.2 \mathrm{~Hz}$, the transition area with a width of $15 \mathrm{~mm}$ is about three times wider than the thermal diffusion length $(4.5 \mathrm{~mm}$ in cast iron).

\section{Thermal resistance characterisation}

Once the functional installation of the non-destructive test bench completed, the study focused on academic samples representative of the liner-engine block interfaces. The following results have been obtained with series of 300 infrared frames quantized on a 12 bit dynamics; the acquisition sequence varies from 20 to 200 seconds, according to the modulation frequency, for an acquisition rate of $15 \mathrm{~Hz}$ with the AGEMA 900LW.

\subsection{Academic measurements of thermal resistances}

The first thermal resistance measurements were realised in a configuration where cast iron and aluminium plates were simply joined. Two cast iron plates were tested: $2 \mathrm{~mm}$-thick and painted, $3 \mathrm{~mm}$-thick and phosphated. Since these first tests only aimed to prove the ability of the method to measure contact resistances, only 1D model was used. First series of measurements were realised with the coated cast iron plates alone. In this case, the coating thickness was measured, the cast iron properties being supposed known, and the thermal conductivity of the coating was identified. Then, second series of measurements were realised with the cast iron plates joined to a $10 \mathrm{~mm}$-thick aluminium plate. The inverse procedure provided the thermal resistance values presented in table 1.

Moreover, in the phosphated case, a simultaneous identification of the thermal resistance and of the cast iron thickness led to the correct value of the depth of the 
interface $(2.97 \pm 0.06 \mathrm{~mm})$, with the same resistance value $\left(2.2610^{-3} \pm 0.2510^{-3}\right.$ $\left.\mathrm{K} \cdot \mathrm{m}^{2} \cdot \mathrm{W}^{-1}\right)$.

\subsection{Resistance measurements under loading}

The experimental device allows the application of a force on the sample perimeter, while keeping an optical access at the centre of the front side. The spaces between cast iron and aluminium plates are measured by inductive (Foucault's currents) displacement sensors: three sensors are at the plate perimeter, on the force transmission area, and one is behind the centre of the free surface. The sensors are screwed in the aluminium plate and the total force applied to the sample is measured. The average temperature level due to the use of the spotlights causes some additional deformations. A thermomechanical modelling with ABAQUS ${ }^{T M}$ software gives a space of $4.57 \mu \mathrm{m}$ at the interface centre, for a load of $6 \mathrm{MPa}$ and a temperature rise in front surface of $63^{\circ} \mathrm{C}$.

Figure 5 shows the phase map for a modulation frequency of $0.05 \mathrm{~Hz}$ with a 2 $\mathrm{mm}$-thick cast iron plate and a $10 \mathrm{~mm}$-thick aluminium plate subjected to a force of $245.7 \mathrm{kN}$ on the perimeter. In this case, both plates, actually not perfectly plane, are not simply joined but straightened out too. The central displacement sensor clearly appears at the centre of the sample. The estimated air thickness or thermal resistances (between 2 and $7.10^{-4} \mathrm{~K} \cdot \mathrm{m}^{2} . \mathrm{W}^{-1}$ ) are shown on figure 6 .

In order to reach some lower thermal resistance values, it is necessary to apply a pressure at the interface. Bezerra Filho [8] had already measured resistances ranging from $10^{-5}$ to $510^{-5} \mathrm{~K} . \mathrm{m}^{2} . \mathrm{W}^{-1}$ at a copper-copper interface in vacuum and under loads of $5.79 \mathrm{MPa}$ and $2.21 \mathrm{MPa}$. Here, the use of a convex aluminium plate allowed forcing the cast iron plate ( $2 \mathrm{~mm}$-thick) to come into contact with the aluminium plate at the centre. Figure 7 shows the phase maps obtained in this configuration (this time, with no displacement sensor), the pressed zone appearing clearly at the centre. As far as the pressed area is strongly localized, the contact resistance is particularly non-uniform; then, the numerical inversion becomes more difficult. Finally, the minimum thermal resistance estimated at the sample centre is of about $1.6510^{-5} \mathrm{~K} \cdot \mathrm{m}^{2} \cdot \mathrm{W}^{-1}$.

\subsection{Application to a liner - engine block interface}

The method has been finally applied to a DV4 cut engine block [6]. The cuttings are made as far as possible from the interface to control (figure 12), in order to limit the disruptions on the air layer. The aluminium side $(5.2 \mathrm{~mm}$-thick) is black painted and the liner thickness is here $2.55 \mathrm{~mm}$. The photothermal measurements give a thermal resistance of $2.6710^{-5} \pm 1.6910^{-5} \mathrm{~K} \cdot \mathrm{m}^{2} \cdot \mathrm{W}^{-1}$. A simultaneous estimation of the thermal resistance and its depth provides an aluminium thickness of $5.03 \pm 0.24 \mathrm{~mm}$ and a thermal resistance of $2.5510^{-5} \pm 0.9510^{-5} \mathrm{~K} \cdot \mathrm{m}^{2} . \mathrm{W}^{-1}$.

\section{4. Conclusion}

The quantitative characterization of the contact thermal resistance at the cast iron - aluminium interface has been realized successfully. The measured contact thermal resistances go down from $210^{-3} \mathrm{~K} \cdot \mathrm{m}^{2} . \mathrm{W}^{-1}$ when the cast iron and aluminium plates are simply joined, to values between 2 and $710^{-4} \mathrm{~K} \cdot \mathrm{m}^{2} . \mathrm{W}^{-1}$ when a force of $150 \mathrm{kN}$ is applied on the plates perimeter, which are straightened out.

Applied to a liner-engine block interface, the method provides resistances of about $210^{-5} \mathrm{~K}^{2} \mathrm{~m}^{2} . \mathrm{W}^{-1}$, matching the values obtained when the cast iron plate is 
pressed against the aluminium plate. Such results are encouraging for potential industrial application of the method to the characterization of the liner - engine block interface, but the quantitative detection of $2 D$ defects at the interface will require a 3D modelling to make the most of phase maps.

\section{REFERENCES}

[1] M. LAURENT, Contribution à l'étude des échanges de chaleur au contact de deux matériaux, Thèse d'état - Lyon, 1969.

[2] C. SAINT-BLANQUET, Etude du transfert de chaleur entre deux solides accolés en régime thermique sinusoïdal, Thèse de doctorat - Université de Nantes, 1970.

[3] E. VAN SCHEL, M. HEURET, C. BISSIEUX, M. REGALIA, M. EGEE, A. BAILLY, Résistance thermique de contact entre matériaux métalliques : mesure par radiométrie photothermique. Modélisation, expérimentation et application, Revue générale de thermique - 36, pp. 321-331, 1992.

[4] H. PRON, Application des effets photothermiques et thermomécanique à l'analyse des contraintes appliquées et résiduelles. Utilisation d'une caméra infrarouge à mosaïque de détecteurs, Thèse de Doctorat - Université de Reims, 2000.

[5] D. WU, G. BUSSE, Lock-in thermography for nondestructive evaluation of materials, Revue générale de thermique - 37, p 693-703, 1998.

[6] P. LALOUE, Thermographie infrarouge photothermique appliquée à la caractérisation non destructive de l'interface chemise - bloc dans les moteurs automobiles, Thèse de Doctorat - Université de Reims, 2003.

[7] J.V. BECK, K.J. ARNOLD, Parameter estimation in engineering and science, J. Wiley ed., 1977

[8] C.R. BEZERRA FILHO, Etude des résistances thermiques de contact en régime périodique, Thèse de doctorat - INSA Lyon, 1998.

\begin{tabular}{|l|c|c|}
\hline & Painted $(2 \mathrm{~mm})$ & Phosphated $(3 \mathrm{~mm})$ \\
\hline Coating conductivity $\left(\mathrm{W} \cdot \mathrm{m}^{-1} \cdot \mathrm{K}^{-1}\right)$ & $0.360 \pm 0.008$ & $1.78 \pm 0.24$ \\
\hline Contact resistance $\left(\mathrm{K} \cdot \mathrm{m}^{2} \cdot \mathrm{W}^{-1}\right)$ & $1.9710^{-3} \pm 0.0710^{-3}$ & $2.3810^{-3} \pm 0.2610^{-3}$ \\
\hline Equivalent air layer thickness $(\mu \mathrm{m})$ & 62 & 75 \\
\hline
\end{tabular}

Table 1. Estimated coating conductivities and thermal resistances between simply joined cast-iron plates

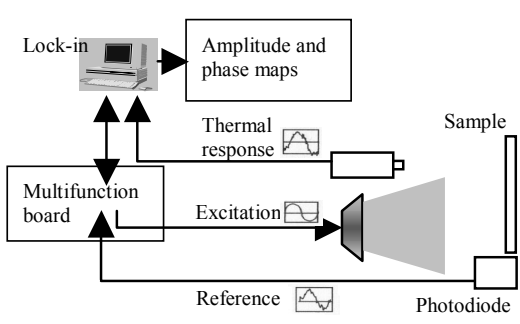

Fig. 1. Experimental device

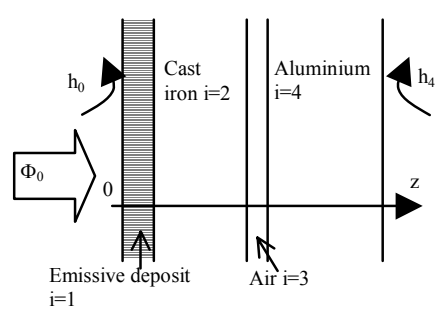

Fig. 2. Four-layer structure diagram 
http://dx.doi.org/10.21611/qirt.2004.041

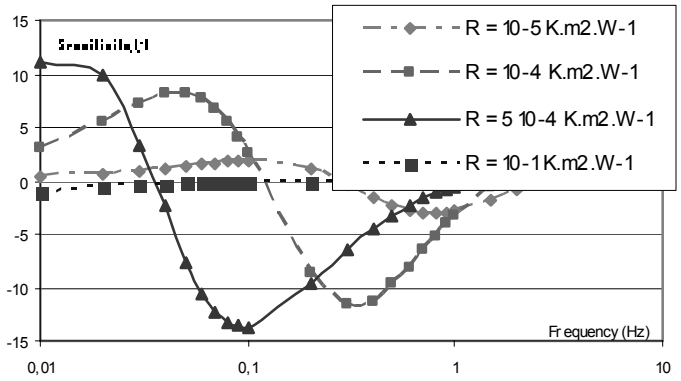

Fig. 3. Phase sensitivity evolution for different values of the thermal resistance
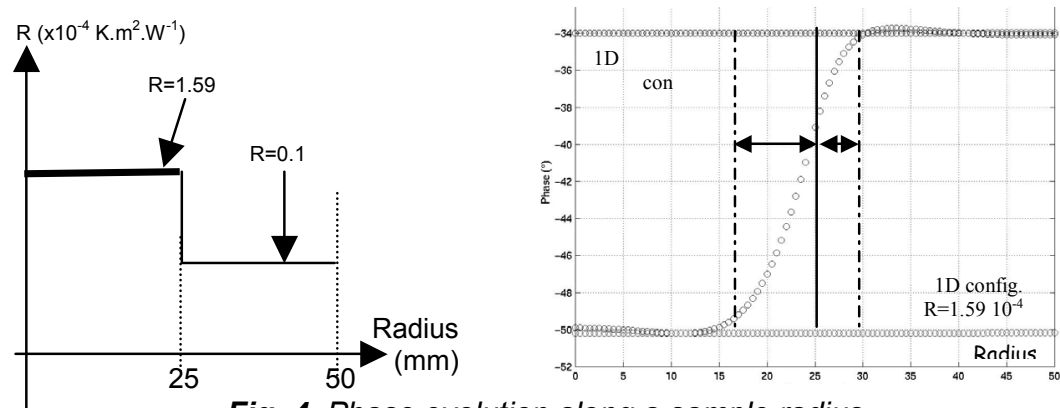

Fig. 4. Phase evolution along a sample radius

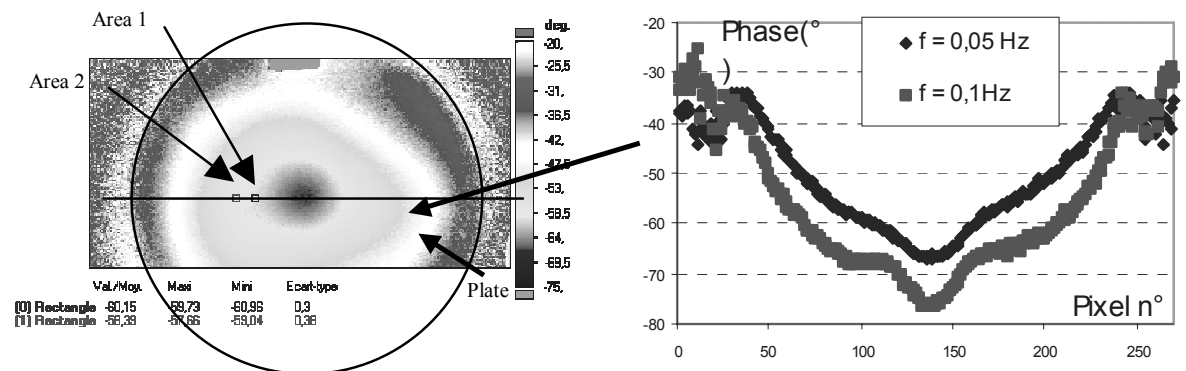

Fig. 5. Phase map at a modulation frequency of $0.05 \mathrm{~Hz}$

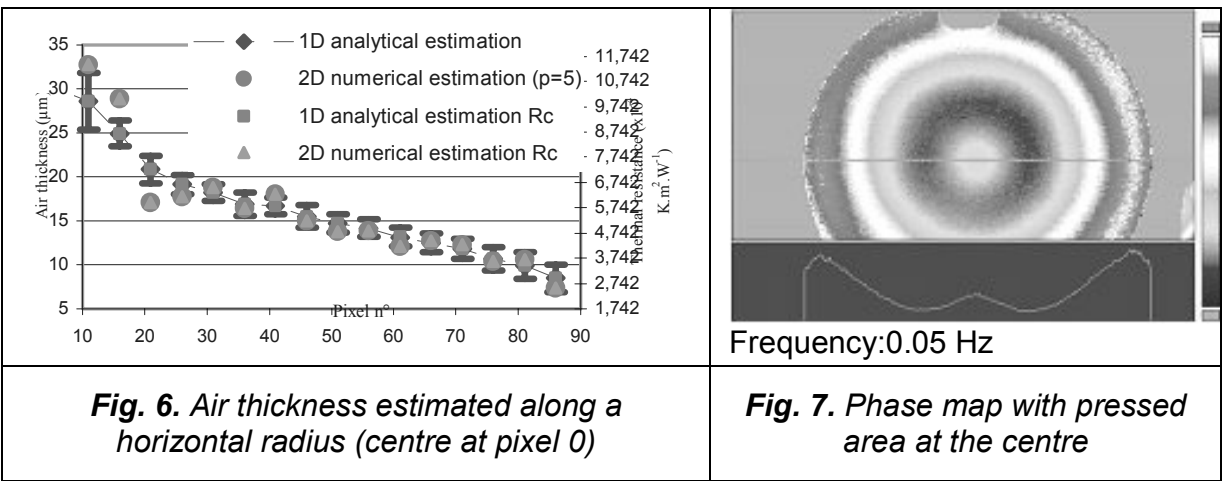

